\title{
EL INCUMPLIMIENTO DE LA LEGISLACIÓN LABORAL COMO IMPEDIMENTO PARA LA IMPLEMENTACIÓN INTEGRAL DE POLÍTICAS DE RESPONSABILIDAD SOCIO-LABORAL EN LAS EMPRESAS PRIVADAS
}

\section{Breach of labor legislation as an impediment for the integral implementation of labor social responsibility policies in private companies}

\author{
Claudia Sofía Valdeiglesias Pacheco ${ }^{1, \mathrm{a}, ~}{ }^{=}$, Luis Fabricio Sota Tamayo ${ }^{1, \mathrm{~b}}$ \\ 1 Universidad Andina del Cusco, Cusco, Perú. \\ a Magíster en Derecho de la Empresa \\ b Abogado \\ ”cvaldeiglesias@uandina.edu.pe
}

Citar como: Valdeiglesia, CS., Sota, LF. (2018). El incumplimiento de la legislación laboral como impedimento para la implementación integral de
políticas de responsabilidad socio-laboral en las empresas privadas. Rev Yachay, 7(1), 446-450.

Recibido: 16-09-2018; Aceptado 07-12-2018

\section{Introducción}

En la actualidad, la 'responsabilidad social empresarial' (RSE) se ha convertido en un aspecto importante que las empresas implementan frente a sus diferentes grupos de interés sin que aún haya sido comprendida a cabalidad. En consecuencia, las políticas de RSE adoptadas por las empresas son aplicadas parcialmente y no a la totalidad de sus stakeholders (partes interesadas), considerando dentro de este grupo a sus colaboradores o trabajadores.

En este orden de ideas, las políticas de responsabilidad socio-laboral son escasas o inexistentes, considerando que muchas empresas no cumplen con lo mínimo legal establecido en la normativa de materia laboral, siendo esta la base, o presupuesto, principal que deben cumplir las instituciones a efectos de que puedan instituir políticas adicionales de RSE en lo laboral.

En consecuencia, una empresa no puede jactarse de ser socialmente responsable con sus trabajadores cuando no son respetados en la observancia de sus derechos legales mínimos, por lo contrario, un gran número de empresas adoptan mecanismos para eludir las obligaciones jurídicas con sus colaboradores.

Por lo antes expuesto, el presente artículo busca establecer los alcances y relación entre la implementación de un sistema de gestión basado en la RSE con los trabajadores y el cumplimiento de las normas legales laborales.

\section{Responsabilidad social empresarial (RSE)}

La RSE implica que las empresas adopten de forma estratégica una serie de políticas y acciones económicas, legales y éticas para cumplir con sus responsabilidades en relación con sus grupos de interés o, denominados en inglés stakeholders, observando las expectativas de estos.

En este entender, la RSE es una forma ética de gestión, que implica la inclusión de las expectativas de todos los stakeholders alrededor de la empresa, con el fin de lograr el desarrollo sostenible; entendiendo a los stakeholders como los grupos de interés que están constituidos por aquellos que son, pueden o creen ser afectados por algún aspecto de las actividades de la empresa y, aquellos que tienen o pueden tener algún interés o pueden afectar a la organización de estas (Díaz, D.; Filomeno, K.; Rizo Patrón, C., 2007).

Algunos de los stakeholder —o grupos de interés de una empresa - pueden ser: los consumidores, clientes, proveedores, accionistas, trabajadores, medio ambiente, etc. En consecuencia, es importante la relación entre estos actores, empresa-grupo de interés, en busca del beneficio común. 
La realidad ha demostrado que la economía de mercado se basa en la ética empresarial, en la alta productividad del trabajo, en la organización rigurosa de la actividad empresarial, en la responsabilidad de los socios por los compromisos hechos, en la capacidad de la gente de negocios para asegurar con un mejor trabajo y condiciones de vida a sus empleados. No es suficiente que los propietarios y gerentes afirmen la necesidad de responsabilidad social y el comportamiento ético de la política de la empresa. Las acciones en este campo, deben intensificarse para que la cultura de la empresa determine que los responsables de la toma de decisiones encuentren la promoción y el control sobre la responsabilidad social y la actitud ética, cuando los propietarios y gerentes decidan los resultados económicos que deben lograrse (Botescu, I., Nicodim, L. \& Condrea, E. , 2008).

a) Responsabilidad socio laboral

Ahora que se tiene un alcance general de lo que es la RSE, es necesario precisar qué es la responsabilidad socio laboral de las empresas cuyo significado parte, justamente, de lo ya mencionado en el acápite precedente.

En este orden de ideas, la responsabilidad socio laboral de las empresas, implica la aplicación o implementación de aquellas acciones y políticas que influyen positivamente en la empresa, teniendo como fuente el bienestar de las personas que trabajan en ella, es decir, los trabajadores o colaboradores; brindándoles condiciones adecuadas de trabajo que vayan más allá del cumplimiento de la legislación laboral. Para un completo entendimiento de este aspecto, definiremos como trabajadores o colaboradores a todas las personas naturales que realizan una labor — de cualquier clase — en beneficio de la empresa y del suyo propio. Incluye a todas las personas que mantienen una relación de subordinación, así como a los colaboradores contratados a través de un servicio por un periodo de tiempo determinado o indeterminado y que realizan labores por más de 4 horas diarias (Ciancaglini, 2013).

Entonces, la responsabilidad social laboral de las empresas constituye el trato ético y observancia de las normas legales, que estas deben cumplir con sus trabajadores, garantizándoles el respeto de sus derechos fundamentales, adecuados ambientes de trabajo, clima laboral, capacitaciones, actividades recreativas, entre otros; teniéndolos como uno de sus grupos de interés más importantes, puesto que hacen posible la existencia y desarrollo de la empresa, dentro de una relación de interdependencia.

La RSE con los colaboradores, empieza por el respeto a su persona; implica también, promover el ejercicio de sus derechos laborales - tales como los de sindicalización, de condiciones de trabajo, remuneración, jornada laboral, etc.-—; todos estos reconocidos en normas nacionales e internacionales, como los convenios de la OIT, legislación del Perú, los estándares internacionales como la Norma SA8000 (Social Accountability International, Norma de responsabilidad social con trabajadores), ISO 9000 (Estándares para calidad de productos y procesos), ISO 14000 (Uso y cuidado del medioambiente), ISO 26000 (de responsabilidad social). (Valdeiglesias Pacheco, 2012).

\section{b) Condiciones para ser una empresa socialmente responsable con los trabajadores}

La primera, y más importante, condición para que una empresa pueda considerarse socialmente responsable con sus trabajadores es el cumplimiento estricto de la legislación laboral vigente, pues esta es la base para poder aplicar políticas adicionales en la relación y desarrollo laboral de este grupo de interés.

Adicionalmente, se tienen los siguientes criterios a cumplir para ser considerada una empresa socialmente responsable con los colaboradores.

- Prohibición de trabajos forzados: esto implica que los trabajadores deben tener conocimiento de los términos y condiciones laborales a los cuales están sujetos y no deben estar expuestos a presión o maltrato físico, psicológico, ni miedo o intimidación. Por otro lado, el trabajador debe tener derecho a salir del centro de trabajo después de completar su día laborable y es libre de concluir la relación laboral siempre que lo notifique con tiempo razonable de antelación a su empleador.

- Salud y seguridad de los trabajadores: en este aspecto la empresa debe proveer un ambiente de trabajo seguro y saludable, tomará medidas para evitar accidentes y lesiones durante la actividad laboral. La empresa debe proporcionar por cuenta propia equipos de protección personal apropiados para su personal, servicios higiénicos, agua potable e instalaciones en adecuadas condiciones sanitarias.

Libertad de asociación y derecho de negociación colectiva: la empresa debe respetar el derecho que tiene el personal para formar, afiliarse, organizar sindicatos y a negociar colectivamente. Del mismo modo, la empresa debe garantizar que los representantes del personal no sean objeto de discriminación, acoso, intimidación o represalias por formar parte de un sindicato o, por participar en actividades sindicales. 
- Igualdad y no discriminación: lo cual significa que la empresa no debe auspiciar ningún tipo de discriminación en la contratación, remuneración, acceso a la capacitación, promoción, despido o jubilación; teniendo como base la raza, origen social o nacionalidad, religión, discapacidad, género, orientación sexual, participación sindical o cualquier otra condición que pueda dar origen a cualquier tipo de discriminación. La empresa no debe permitir ningún comportamiento que sea amenazador, abusivo, explotador o sexualmente coercitivo, todo esto incluye gestos, lenguaje y contacto físico en el lugar de trabajo y donde sea aplicable, tanto en residencias, asicomo otras instalaciones para el uso de los trabajadores ofrecidas por la empresa.

- Medidas disciplinarias: la empresa debe tratar a todos sus colaboradores con dignidad y respeto; no utilizará castigos corporales, coerción mental o física ni abuso verbal; asimismo, no aplicará multas, amenazas ni permitirá actos de intimidación o reducciones arbitrarias en el salario. Existen mecanismos no arbitrarios, formales y escritos para informar a los colaboradores de su desempeño en el trabajo sin que medie ningún tipo de maltrato.

- Horario de trabajo: en este aspecto, la empresa debe respetar y cumplir con la jornada laboral que establezca la ley, sin que esta exceda las 48 horas semanales. Por otro lado, se debe otorgar al personal un día libre por cada periodo de 7 días de trabajo. Las horas extras deben ser voluntarias y solo cuando sean necesarias para cumplir una demanda del negocio y si la empresa es parte de un acuerdo de negociación colectiva, estas horas extraordinarias serán rembolsadas con pago adicional superior a la de las horas normales, pero en ningún caso, debe superar las 12 horas por semana ni pueden ser solicitadas de forma regular.

- Remuneración: este aspecto implica que la empresa debe garantizar que los salarios que paga por una semana de trabajo cumplan con las normas legales mínimas, de manera que sean suficientes para cubrir las necesidades básicas de los colaboradores. La empresa garantizará que no se realicen deducciones de los salarios por razones disciplinarias, asimismo se garantizará que la composición salarial y los beneficios se detallen claramente y en forma habitual a los trabajadores; el pago debe ser justo y oportuno. También se debe asegurar que no se realicen prácticas de contratación irregulares; las horas extraordinarias deben ser rembolsadas según la legislación nacional (Norma SA8000 de responsabilidad social).

\section{Generalidades de la legislación laboral}

En el Perú, existen numerosos cuerpos normativos que regulan diferentes aspectos de la relación laboral en las empresas privadas; sin embargo, en el presente acápite se pretende sistematizar las principales que deben ser cumplidas para poder, adicionalmente, aplicar políticas de responsabilidad social empresarial:

- La Constitución Política del Perú, en su Art. $2 .^{\circ}$ numeral 15, establece que toda persona tiene derecho a trabajar libremente y al reconocimiento de la libertad de trabajo; asimismo en el numeral 24, inciso 'b' del mismo artículo, señala la prohibición de la esclavitud, la servidumbre y la trata de seres humanos en cualquiera de sus formas y, el Art. 23 indica, que nadie puede ser obligado a trabajar sin que medie consentimiento y una retribución, la misma que debe ser equitativa y suficiente, es decir, ninguna relación laboral puede limitar el ejercicio de los derechos constitucionales, ni rebajar las condiciones del trabajador. Nadie está obligado a prestar servicios sin una retribución o sin su libre consentimiento.

- El Texto Único Ordenado del Decreto Legislativo N. ${ }^{\circ} 728$, «Ley de productividad y competitividad laboral», tiene entre sus principales objetivos, el de promover el acceso al empleo productivo, mejorar los niveles de empleo adecuado en el país de manera sustancial, así como combatir el desempleo y el subempleo, garantizar la seguridad en el empleo y los ingresos de los trabajadores, respetando las normas constitucionales de estabilidad laboral, fomentar la capacitación y formación laboral de los trabajadores como un mecanismo de mejoramiento de sus ingresos y la productividad del trabajo, unificar las normas sobre contratación laboral y consolidar los beneficios sociales existentes.

- El Decreto Supremo N. ${ }^{\circ}$ 007-2002-TR, «Texto único ordenado de la ley de jornada de trabajo, horario y trabajo en sobretiempo», busca principalmente, establecer los lineamientos para establecer el tiempo máximo de las jornadas de trabajo, las jornadas en horario nocturno, el otorgamiento y prestación del trabajo en sobretiempo.

- $\quad$ El Decreto Legislativo N. ${ }^{\circ} 713$, consolida la legislación sobre descansos remunerados de los trabajadores sujetos al régimen laboral de la actividad privada.

- La Ley N. $^{\circ} 27735$, ley que regula el otorgamiento de las gratificaciones para los trabajadores del régimen de la actividad privada por fiestas patrias y navidad; la cual establece el derecho de los trabajadores sujetos al régimen laboral de la actividad privada, a percibir dos gratificaciones en el año: una con motivo de fiestas patrias y la otra con ocasión de la navidad. Este beneficio resulta de aplicación sea cual fuere la modalidad del contrato de trabajo y el tiempo de prestación de servicios del trabajador.

El Decreto Supremo N. ${ }^{\circ}$ 001-97-TR, Texto único ordenado de la ley de compensación por tiempo de servicios; tiene como objetivo establecer los lineamientos para el otorgamiento de la compensación por tiempo de servicios, la cual tiene la calidad 
de beneficio social de previsión de las contingencias que origina el cese en el trabajo y de promoción del trabajador y su familia. Este beneficio comprende a trabajadores sujetos al régimen laboral común de la actividad privada que cumplan, cuando menos en promedio, una jornada mínima diaria de cuatro horas.

- $\quad$ La Ley N. ${ }^{\circ} 29783$, Ley de seguridad y salud en el trabajo; tiene como objetivo promover una cultura de prevención de riesgos laborales en el país. Para ello, cuenta con el deber de prevención de los empleadores, el rol de fiscalización y control del Estado y la participación de los trabajadores y sus organizaciones sindicales quienes, a través del diálogo social, velan por la promoción, difusión y cumplimiento de la normativa sobre la materia.

- La Ley n. ${ }^{\circ} 27942$, Ley de prevención y sanción del hostigamiento sexual; la cual tiene por objeto prevenir y sancionar el hostigamiento sexual producido en las relaciones de autoridad o dependencia, cualquiera sea la forma jurídica de esta relación. Su ámbito de aplicación comprende, entre otros, los centros de trabajo públicos y privados: a los trabajadores o empleadores, al personal de dirección o de confianza, al titular, asociado, director, accionista o socio de la empresa o institución; asimismo, a los funcionarios o servidores públicos cualquiera sea su régimen laboral.

- $\quad$ El Decreto Supremo N. ${ }^{\circ}$ 010-2003-TR, Texto único ordenado de la ley de relaciones colectivas de trabajo; el cual, entre sus lineamientos principales, reconoce a los trabajadores el derecho a la sindicación sin autorización previa, para el estudio, desarrollo, protección y defensa de sus derechos e intereses y el mejoramiento social, económico y moral de sus miembros. La afiliación es libre y voluntaria, no puede condicionarse el empleo de un trabajador a la afiliación, no afiliación o desafiliación; obligársele a formar parte de un sindicato, ni impedírsele hacerlo. El Estado, los empleadores y los representantes de uno u otros, deberán abstenerse de toda clase de actos que tiendan a coartar, restringir o menoscabar en cualquier forma el derecho de sindicalización de los trabajadores y, de intervenir en modo alguno en la creación, administración o sostenimiento de las organizaciones sindicales que estos constituyan.

\section{Responsabilidad socio laboral y el cumplimiento de las normas legales}

La responsabilidad socio laboral de las empresas, no es un tema independiente al cumplimiento de las normas legales en materia laboral, por el contrario, esta resulta un aspecto complementario en la búsqueda de un trato ético a los trabajadores en el desarrollo de sus actividades laborales que no benefician únicamente a estos, sino también a la misma empresa.

El Perú, se caracteriza por tener un alto nivel de informalidad laboral, pues las empresas buscan incumplir normas legales que consideran de aplicación costosa y que afecta su rentabilidad así, por ejemplo, los contratos a plazo indeterminado son sustituidos por contratos a plazo definido sin que su carácter temporal esté justificado, por tanto, desnaturalizan la relación laboral. Otro aspecto bastante frecuente es el trabajo en sobretiempo sin que sea compensado o remunerado conforme a ley. Así, se podrían referir diferentes aspectos que se dan en la realidad en cuanto al incumplimiento de la ley.

En virtud a lo antes indicado sería importante que las empresas tengan una visión a mediano y largo plazos sobre los beneficios de ser socialmente responsables con sus trabajadores, claro está, partiendo del cumplimiento normativo, pues la experiencia de empresas importantes ha demostrado que los clientes prefieren recibir servicios o adquirir productos que se realicen con respeto a los derechos y dignidad de los trabajadores.

En consecuencia, queda claro que las empresas que se consideran socialmente responsables con sus trabajadores deben evaluar, en primera instancia, el cumplimiento de las normas legales establecidas en el país para, adicionalmente a ello, se puedan aplicar otras políticas tales como: capacitaciones, actividades recreativas, reconocimientos, entre otros.

\section{Conclusiones}

- El cumplimiento de la ley laboral y la aplicación de un sistema de gestión socialmente responsable con los trabajadores si bien es cierto puede generar cuantiosos costos a las empresas, es importante evaluar los beneficios que esto implica; como una mayor oportunidad de ingresar a mercados externos, identificación y compromiso por parte de los trabajadores; lo cual significa un mejor desempeño y productividad; ser sostenible en el mediano y largo plazos, fidelidad y preferencia de clientes y consumidores, buena imagen y reputación pública; aspectos que se verán reflejados en la rentabilidad de la institución.

- Los criterios que deben cumplir las empresas para ser socialmente responsables con sus trabajadores, tiene como fuente principal lo establecido en los cuerpos normativos, y su primer requisito es la observancia y cumplimiento de estos. 
- Es incorrecto calificar a una empresa como socialmente responsable con sus trabajadores, cuando esta solo aplica políticas independientes al cumplimiento de las normas legales en materia laboral de forma aislada, y no como complemento de estas.

\section{Referencias bibliográficas}

Argandoña, A. (enero de 2008). La ética en los negocios. IESE Business School, 08(10), 1-9. Obtenido de https://media.iese.edu/research/pdfs/OP-08-10.pdf

Bedoya, Carlos y Fernández Maldonado, Enrique. (2004). Derechos laborales y responsabilidad social empresarial en el Perú. Lima, Perú: CEDAL.

Botescu, I., Nicodim, L. \& Condrea, E. . (febrero de 2008). Business ethics and the social responsability of the company. Amfiteatru Economic, X(23), 131-135. Recuperado el 3 de diciembre de 2018, de http://apps.webofknowledge.com/full_record.do?product=WOS\&search_mode=GeneralSearch\&qid=3\&SID=7ELp57hLLwyS JEIC5Kj\&page $=1 \&$ doc $=4$

Ciancaglini, I. (2013). De empresas responsables a negocios sostenibles. Obtenido de Perú 2021: http://peru2021.org/de-empresasresponsables-a-negocios-sostenibles/

Díaz, D.; Filomeno, K.; Rizo Patrón, C. (2007). Relación y compromiso con los grupos de interés. Duía práctica para las empresas peruanas. Lima, Perú: Perú 2021. Obtenido de https://es.slideshare.net/dariodiaz2011/stakeholder-engagement-gua-prctica

Valdeiglesias Pacheco, C. S. (2012). Dificultades para la implementación de la norma SA8000 en las empresas peruanas. Pontificia Universidad Católica del Perú. Lima: PUCP. Recuperado el 4 de diciembre de 2018, de http://tesis.pucp.edu.pe/repositorio/handle/123456789/4509

Constitución Política del Perú

Texto Único Ordenado del Decreto Legislativo N. ${ }^{\circ} 728$, Ley de productividad y competitividad laboral

Decreto Supremo N. ${ }^{\circ}$ 007-2002-TR, Texto único ordenado de la ley de jornada de trabajo, horario y trabajo en sobretiempo

Decreto Legislativo $\mathrm{N} \cdot{ }^{\circ} 713$, legislación sobre descansos remunerados de los trabajadores sujetos al régimen laboral de la actividad privada.

Ley $\mathrm{N}^{\circ} 27735$, Ley que regula el otorgamiento de las gratificaciones para los trabajadores del régimen de la actividad privada por fiestas patrias y navidad

El Decreto Supremo N. ${ }^{\circ}$ 001-97-TR, Texto único ordenado de la ley de compensación por tiempo de servicios.

Ley $N .^{\circ} 29783$, Ley de seguridad y salud en el trabajo.

Ley N. ${ }^{\circ} 27942$, Ley de prevención y sanción del hostigamiento sexual

Decreto Supremo N. ${ }^{\circ}$ 010-2003-TR, Texto único ordenado de la ley de relaciones colectivas de trabajo 